\title{
Towards Sensor-Based Health Monitoring Systems for Bridge Decks: A Full-Depth Precast Deck Panels Case Study
}

\author{
Osama Y. Abudayyeh,, ${ }^{1}$ Joseph Barbera, ${ }^{1,2}$ Ikhlas Abdel-Qader, ${ }^{3}$ \\ Hubo Cai, ${ }^{4}$ and Eyad Almaita ${ }^{3}$ \\ ${ }^{1}$ Department of Civil and Construction Engineering, Western Michigan University, Kalamazoo, MI 49008-5314, USA \\ ${ }^{2}$ Reynolds, Smith and Hills Inc., USA \\ ${ }^{3}$ Department of Electrical and Computer Engineering, Western Michigan University, Kalamazoo, MI 49008, USA \\ ${ }^{4}$ School of Civil Engineering, Purdue University, West Lafayette, IN 47907-2051, USA
}

Correspondence should be addressed to Osama Y. Abudayyeh, osama.abudayyeh@wmich.edu

Received 14 June 2010; Revised 6 December 2010; Accepted 17 December 2010

Academic Editor: Farid Taheri

Copyright (C) 2010 Osama Y. Abudayyeh et al. This is an open access article distributed under the Creative Commons Attribution License, which permits unrestricted use, distribution, and reproduction in any medium, provided the original work is properly cited.

Traffic and variable loading conditions greatly influence the performance, durability, and safety of a bridge structure throughout its service life. Continuous monitoring can provide the basis for determining the deterioration rate and for estimating the remaining service life, thus assisting in making important decisions regarding bridge maintenance. This paper presents the design and implementation of a health monitoring system for condition assessment of full-depth precast concrete bridge deck, which was developed for the Parkview Bridge in Kalamazoo, Michigan. This system is composed of a remotely accessible on-site data acquisition system and a sensor network of vibrating wire strain gauges to monitor strain and temperature over given time increments. The system relies on the sensor network embedded in the bridge deck to gather static performance data under different loading conditions to provide condition assessment by collecting, storing, analyzing, and reporting relevant performance data over time. The paper presents a practical case study that mainly focuses on describing the initial steps in the development of the sensor network system, namely, the design (system architecture and data structures) and construction along with examples of how the data is acquired, organized, presented, and analyzed, keeping in mind that the bridge is still early in its life-cycle and has not yet experienced any structural problems.

\section{Introduction}

Bridges are a critical component of the transportation infrastructure. There are approximately 600,000 bridges in the United State according to the U.S. Department of Transportation Federal Highway Administration [1]. Four billion vehicles traverse these bridges daily [2]. Regular inspections and maintenance are essential components of any bridge management program to ensure structural integrity and user safety. This is a grand challenge due to the enormous number of existing bridges.

To assess the condition of a bridge, a few approaches are commonly used in practice. Visual inspection has a long history in bridge condition assessment and documents any sign of cracking, spalling, leaching, deflection and vibration, accidental damage, and deck surface damages. However, assessing the extent of structural deficiency of a concrete bridge is usually unreliable through visual inspections [2]. Coring samples provide a supplementary approach, in which small cores are drilled and concrete samples are obtained and tested in a laboratory. Since samples are taken from small selected portions of the concrete, erroneous conclusions might be reached due to the lack of overall behavioral information throughout the concrete structure. Diagnostic testing is another bridge condition assessment technique in which a bridge is exposed to varying loads and its responses measured and analyzed [3]. Diagnostic testing faces many constraints related to cost and traffic interruption. More importantly, diagnostic testing lacks the capability of continuously monitoring the bridge performance, which 


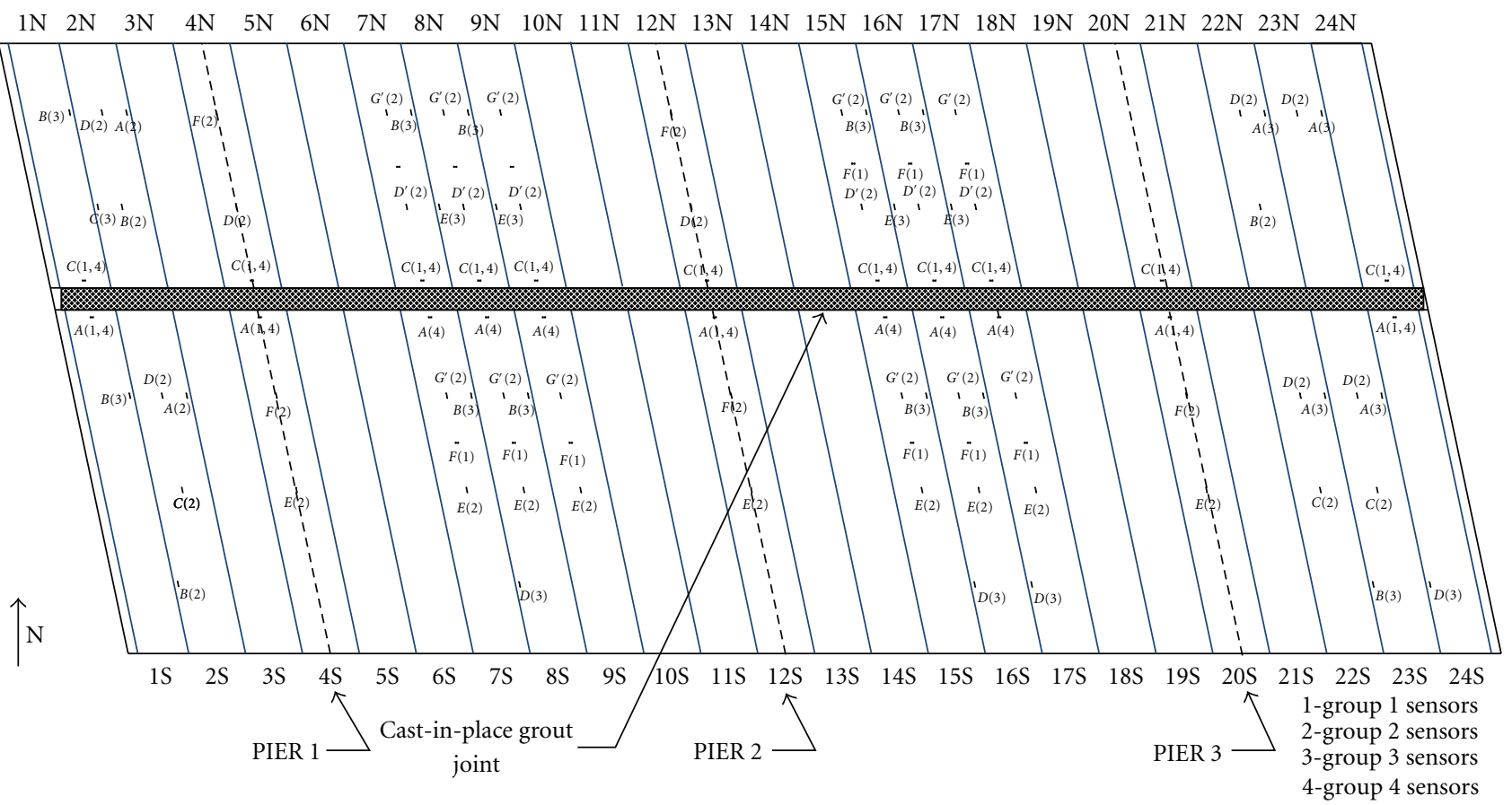

Figure 1: Parkview Bridge deck layout.

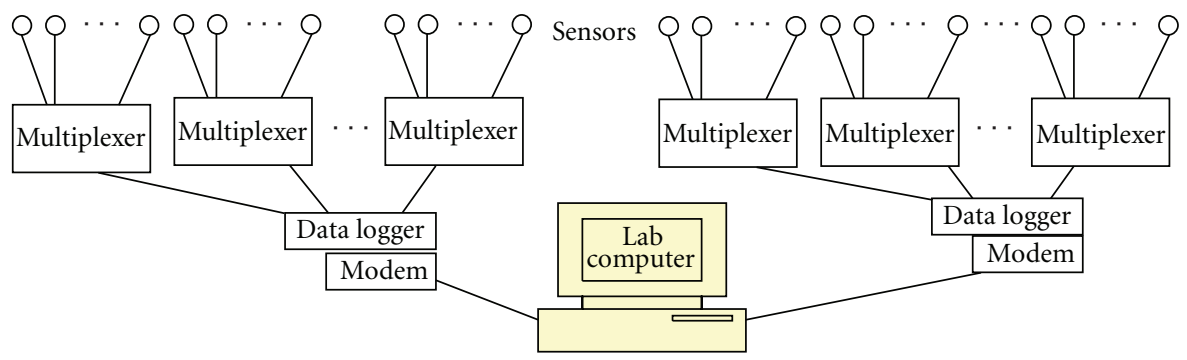

Figure 2: Schematic view of the Parkview Bridge SHM system configuration.

is the key to determining the remaining bridge service life [4].

Even though intensive bridge inspection and maintenance are being performed nationwide, the outcomes are not impressive. It has been reported that of the 600,000 bridges, $12 \%$ have been deemed structurally deficient while another $13 \%$ have been deemed functionally obsolete [1]. With these statistics, $25 \%$ of the nation bridges require immediate attention or repair and may present safety challenges. The appearance of widespread failures in bridges emphasizes the importance of effective continuous monitoring systems so that problems can be identified at early stage and economic measures can be taken to avoid costly replacement and catastrophic bridge failures [5]. Therefore, there is a need for bridge health monitoring technologies to enable continuous monitoring and real-time data collection.

This paper presents a sensor-based bridge health monitoring system developed for the Parkview Bridge in Kalamazoo, Michigan. In this study, a bridge health monitoring system was designed and deployed for a newly constructed bridge that adopted rapid bridge construction techniques using precast concrete technology. Sensors were installed at strategic locations and connected to a remote computer workstation via telephone lines. Continuous bridge condition data are being collected in real time, archived in the laboratory computer workstation, and analyzed to assess the structural performance and integrity.

\section{Concrete Bridge Health Monitoring}

Traffic and variable loading conditions greatly influence the performance, durability, and safety of a bridge structure throughout its service life. In addition to carrying traffic loads, a bridge is exposed to its surrounding environment. Environmental factors such as temperature, humidity, and precipitation can all significantly affect the structural integrity and performance of a bridge as well. The condition of a bridge is never constant and therefore needs to be monitored continuously. Continuous monitoring can provide the basis for determining the deterioration rate 


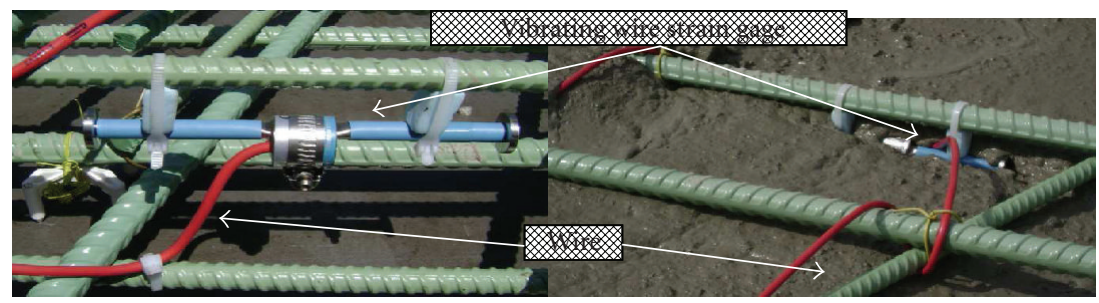

(a) Properly securedsensor

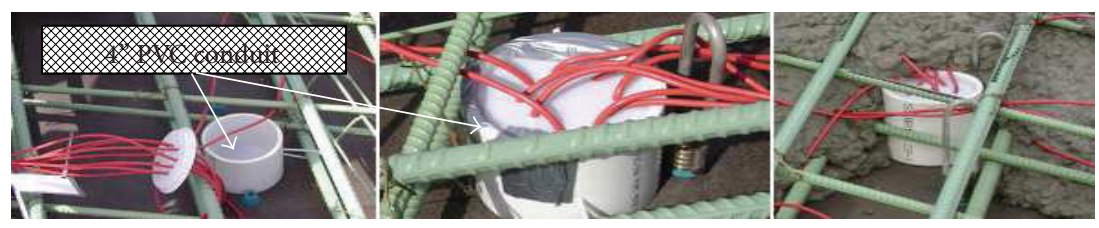

(b) Conduit placement

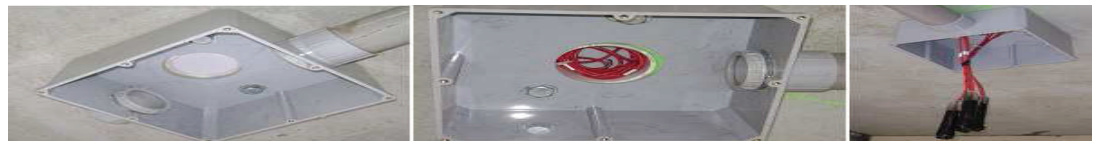

(c) Exposed Conduit, Wire, and Splicing.

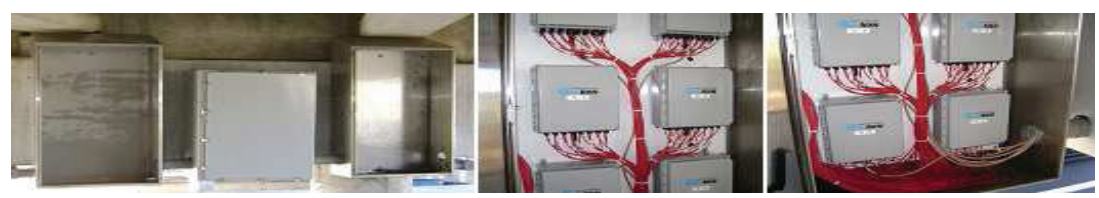

(d) Cabinets and data logging equipment.

Figure 3: The components and wiring of the sensor network.

TABLE 1: Health monitoring case study summary.

\begin{tabular}{lccccc}
\hline Case study & $\begin{array}{c}\text { Types of sensors } \\
\text { used* }\end{array}$ & \# of sensors used & Sensor placement & $\begin{array}{c}\text { Data collection time } \\
\text { intervals }\end{array}$ & Load type monitored \\
\hline $\begin{array}{l}\text { Confederation bridge } \\
\text { (Canada) }\end{array}$ & $\begin{array}{c}(1),(2),(3),(4), \\
(5),(6),(7),(8)\end{array}$ & 389 & Deck, Beam, Pier & Variable & Static/dynamic \\
$\begin{array}{l}\text { Pemiscot county bridge, } \\
\text { Missouri (U.S.) }\end{array}$ & $(1),(3),(4)$ & 64 & Deck, Beam & Static \\
$\begin{array}{l}\text { North halawa valley } \\
\text { viaduct, Hawaii (U.S.) }\end{array}$ & $(1),(4)$ & 200 & Deck, Beam & 5 minutes/2 hours \\
$\begin{array}{l}\text { Parkview bridge, Michigan } \\
\text { (U.S. })\end{array}$ & $(1),(4)$ & 184 & Deck & 10 minutes & Static \\
\hline
\end{tabular}

* Note: sensor types: (1) Vibrating wire strain gage, (2) Fiber optical, (3) Resistance strain gage, (4) Thermocouples, (5) Accelerometer, (6) Tilt-meter, (7) Displacement, and (8) Ice-force.

and for estimating the remaining service life, thus assisting in making important decisions regarding bridge maintenance.

Among many technologies that have been developed to aid bridge condition assessment, sensor technology has attracted enormous research interest due to its capability of continuously monitoring the bridge condition [4-7]. With the advancement in sensor technology, many sensors can be embedded in concrete at different locations, comprising a sensor network for structural health monitoring (SHM). These sensor networks can aid in the determination of the true reliability and performance of a structure by interpreting the data collected.

Applications of sensor-based SHM have been expanding in bridge health monitoring to increase safety and help engineers develop models for determining how a structure is behaving internally. At this moment, however, only few studies on sensor-based SHM in practice are available. Chajes reported on a study, in which strain gauges were used to remove restricted load limitations on three bridges in Delaware [8]. Casas described the usage of fiber optic sensors for bridge monitoring including crack detection, strain monitoring, and temperature monitoring [5]. Howell reported 


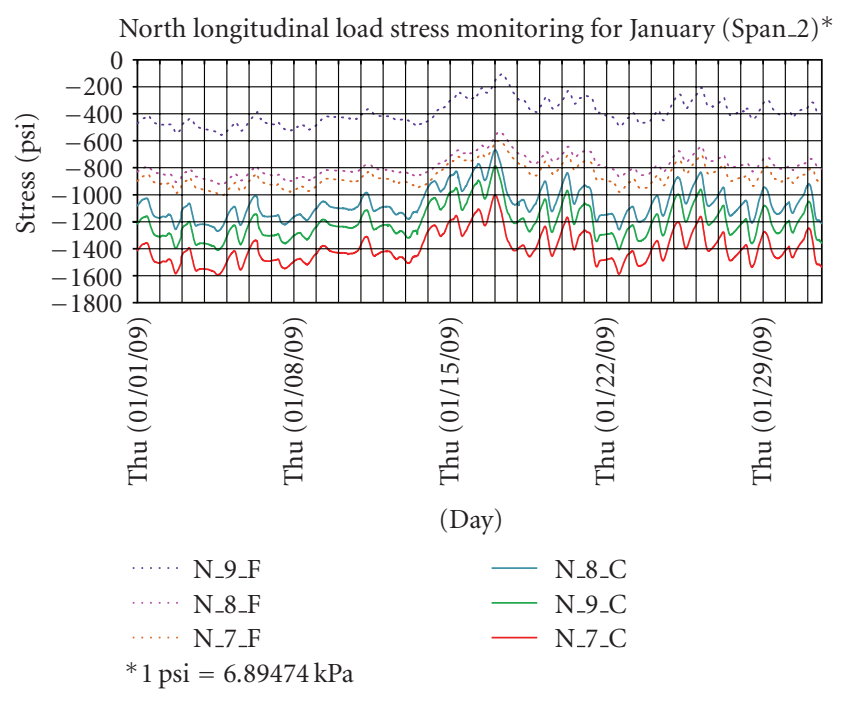

FIgURE 4: North longitudinal load stress monitoring for span two (January).

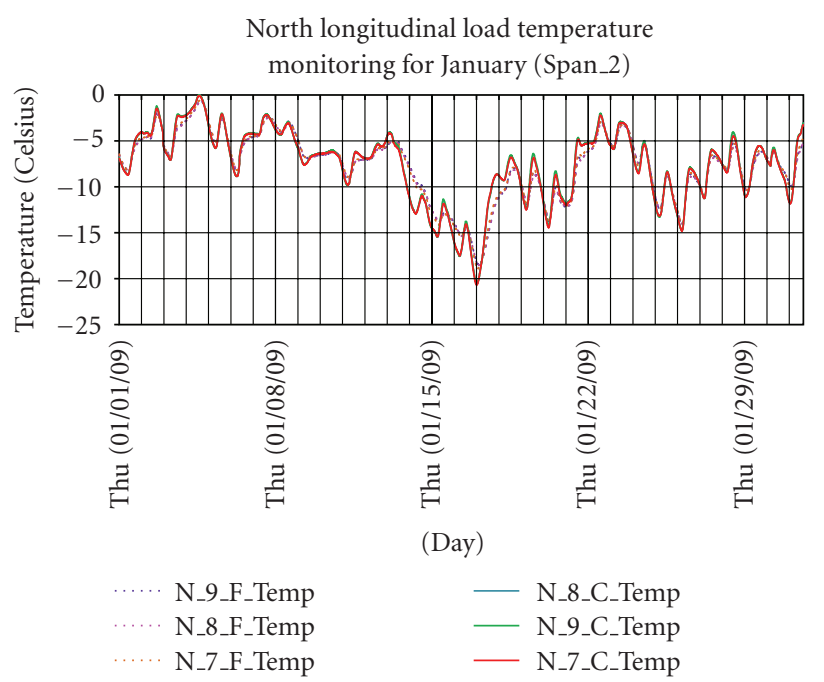

FIGURE 5: North longitudinal load temperature monitoring for span two (January).

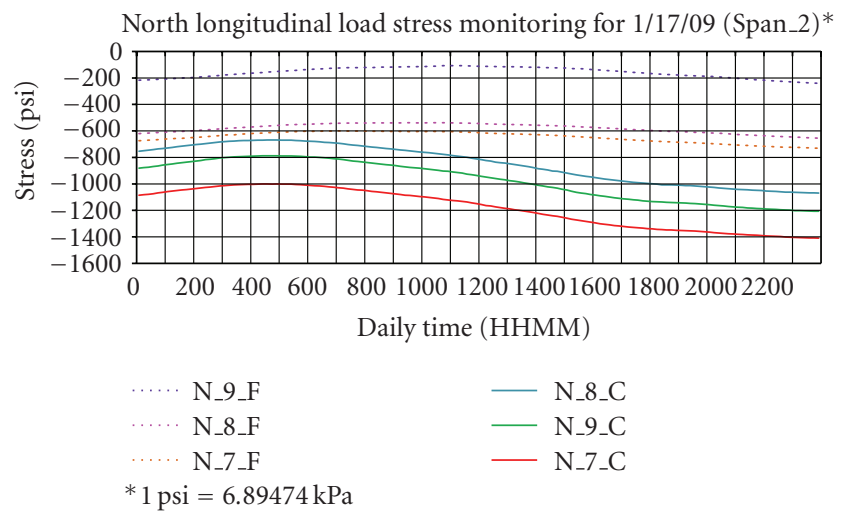

Figure 6: North longitudinal load stress monitoring for span two (1/17/09).

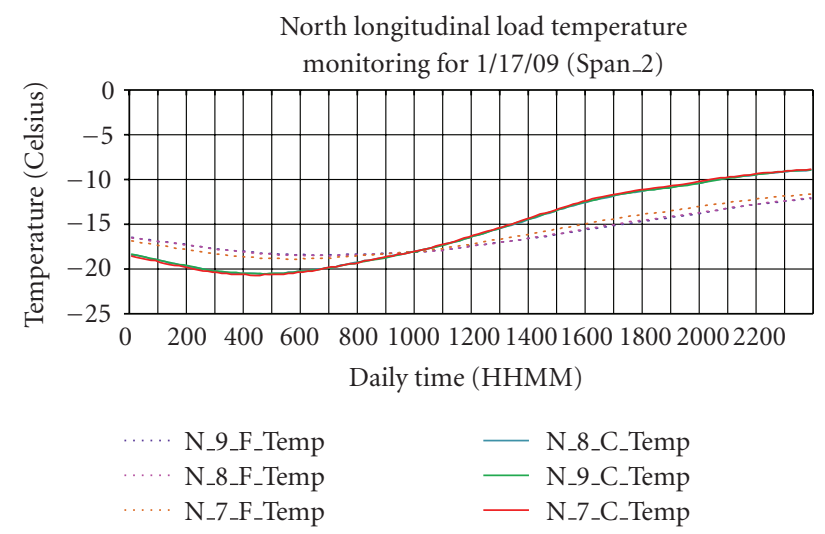

FIGURE 7: North longitudinal load temperature monitoring for span two $(1 / 17 / 09)$.

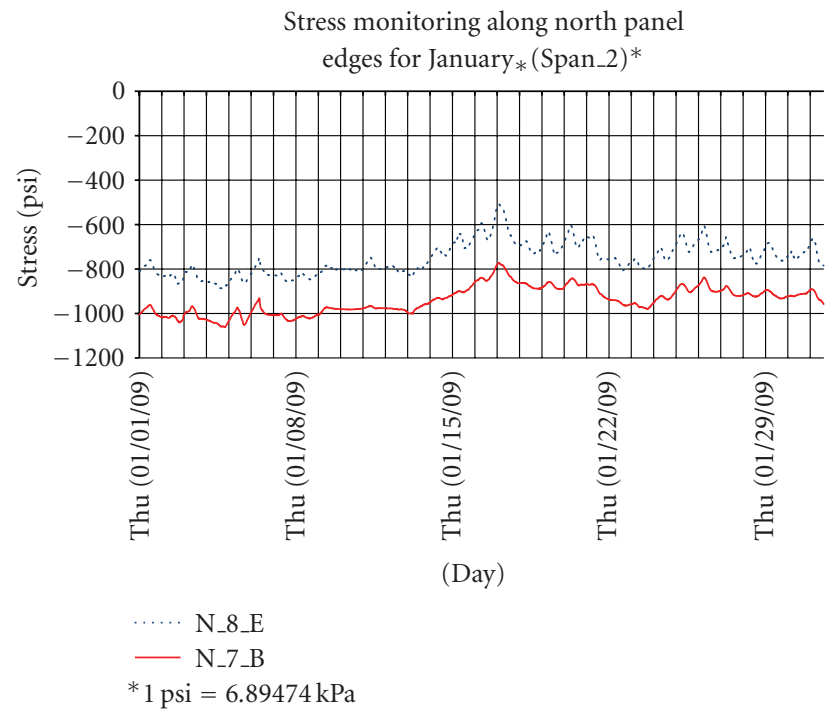

FIGURE 8: Stress monitoring along north panel edge for span two (January).

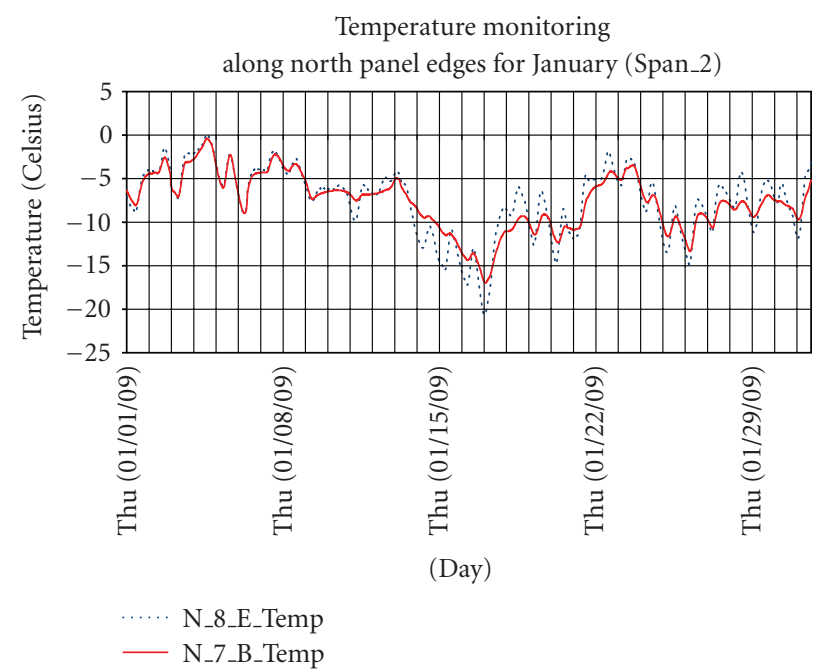

FIGURE 9: Temperature monitoring along north panel edge for span two (January). 


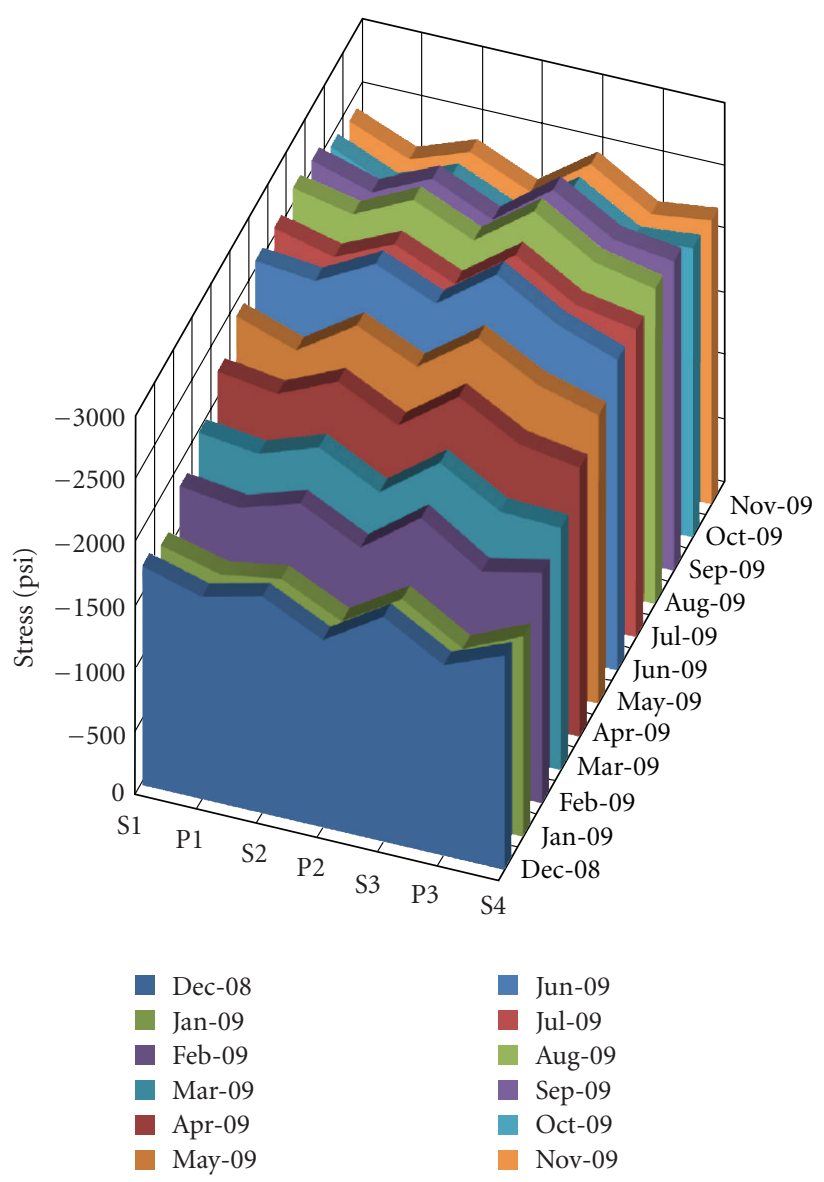

(a) Maximum

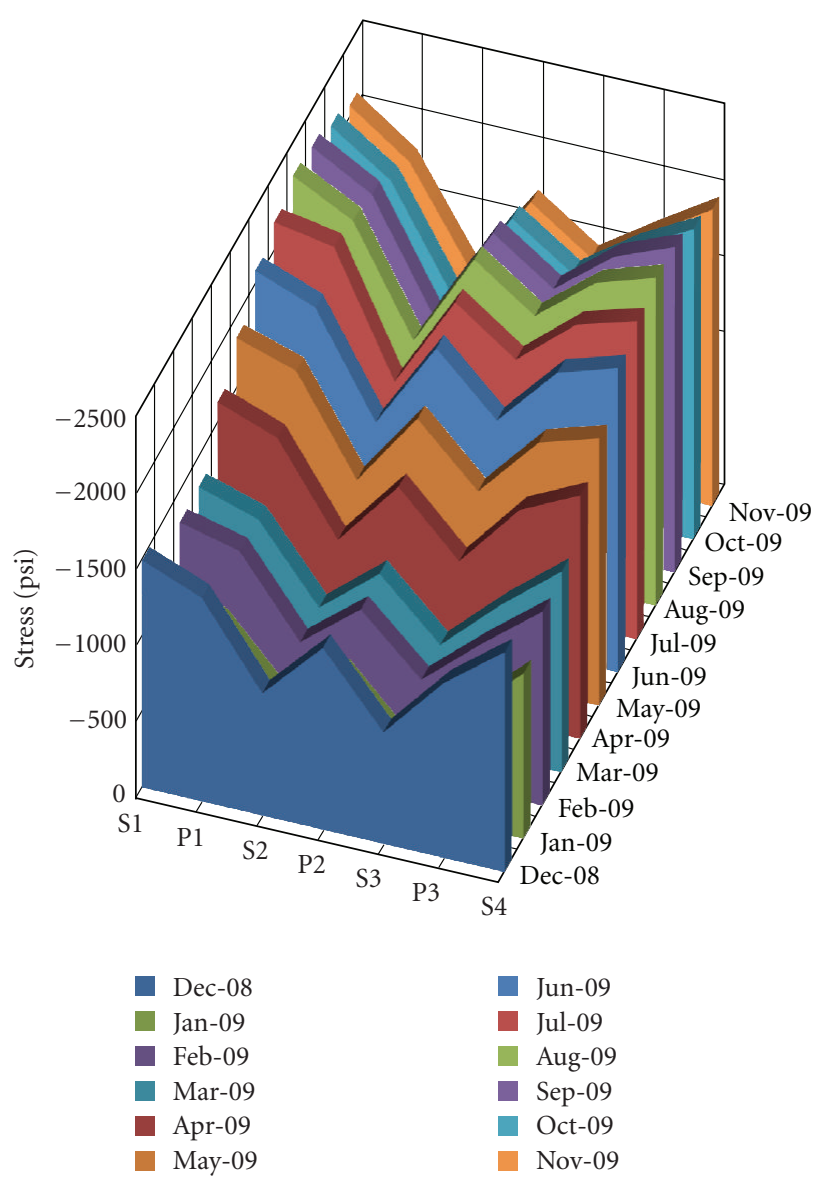

(b) Minimum

FIgURE 10: Maximum and minimum longitudinal stresses (psi)—north panels.

the development of an in-service strain monitoring system and its application in a number of bridges in Delaware [4]. Olund reported a series of bridge health monitoring studies conducted in Connecticut using the sensor technology, with recommendations of sensor selection and system configuration [7]. Table 1 provides a summary of the char-acteristics of some examples of these sensor networks that are already in use [9-11].

These studies demonstrated the applicability of using sensor systems in continuously monitoring the condition of concrete bridges. Observations and findings in these studies laid a foundation for the design and implementation of the sensor network for the Parkview Bridge in Michigan. All the case studies above, except for the Parkview Bridge, had cast-in-place decks. The Parkview Bridge, on the other hand, had precast, full-depth deck panels, making this SHM study different from the others and posing unique challenges.

\section{The Parkview Bridge SHM System Design and Installation}

The Parkview Bridge is the first prefabricated bridge in Michigan to take advantage of rapid bridge construction techniques. A sensor network was designed and deployed to provide an SHM system for monitoring the performance of the bridge's full-depth deck panels. The bridge has four spans and three lanes, with all its major bridge concrete elements including piers, abutments, I-beam girders, and full-depth deck panels prefabricated off-site. The superstructure is composed of type IV AASHTO girders, and the deck is composed of forty eight, nine-inch thick precast reinforced concrete panels. These panels are categorized as North and South. Once the North and South panels were installed on-site, they were joined by a cast-in-place grouted joint. The deck is posttensioned with an added three-inch asphalt wearing surface. An overview of the bridge layout is shown in Figure 1.

3.1. SHM Sensor Network Configuration. Properly placed strain and thermocouple sensors can provide valuable information about structural performance. Additional measuring devices can be used, but only strain and temperature measurements were chosen in this project. The selection was based on the location of the bridge (relatively rural with light traffic) and cost, as well as on the reliability of such sensors, particularly the successful long-term performance of similar sensors (nine years in one instance [10]). To further ensure 


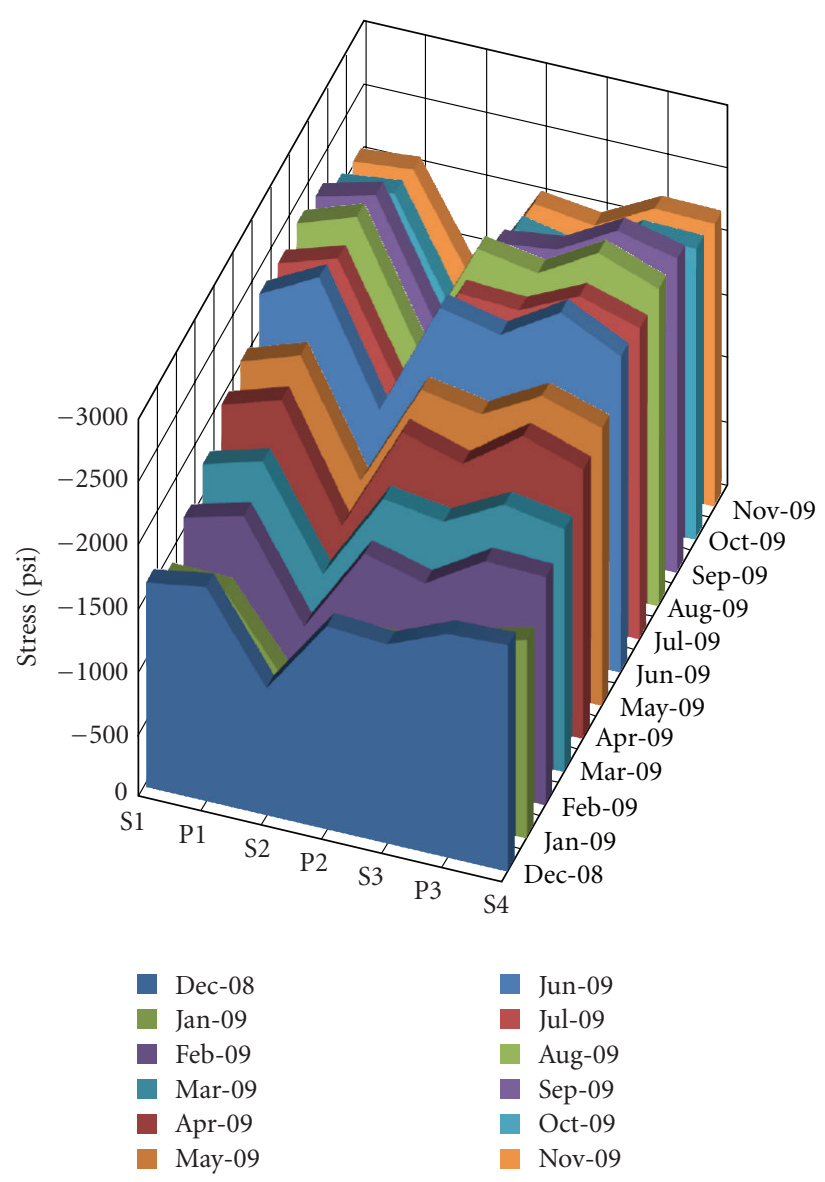

(a) Maximum

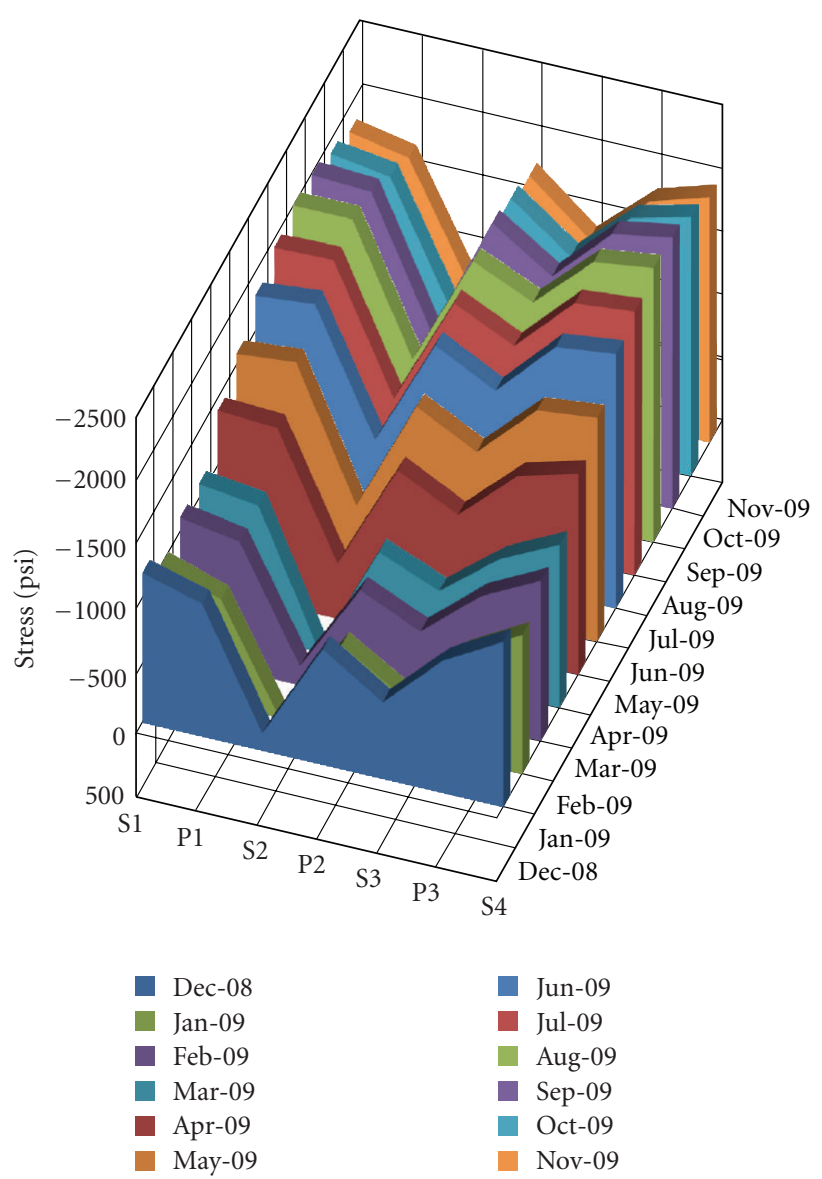

(b) Minimum

FIGURE 11: Maximum and minimum longitudinal stresses (psi)—south panels.

reliability in the sensor network, a number of redundant sensors were installed to allow for continued monitoring in case a sensor stops working. Therefore, the SHM system for the Parkview Bridge is composed of 184 vibrating-wire strain sensors (VWSG) with built-in thermocouples (thermistors) installed in the bridge deck panels. Additionally, the system hardware includes 12 multiplexers, 2 data loggers, 2 modems, a remote computer workstation in a laboratory, and the necessary wiring for communication and data transfer. The sensors and data loggers were calibrated and used per the manufacturer recommendation. They were tested in the laboratory to insure that they were reading correct values before they were placed in the bridge panels. They were installed by the research team and by a certified electrician during the construction phase. The initial temperature and strain values were recorded before placing the sensors in the panel forms. These initial readings are used later in calculating the strain and temperature values after recording the actual readings from the sensors. Figure 2 provides a schematic view of the designed system.

In order to effectively monitor the structural performance, sensors must be placed at strategic locations. The locations of the sensors were based on the structural analysis information provided by the bridge designer. They were installed at and around the locations of maximum stresses and at locations with anticipated future durability issues (i.e., at panel joints and around the closure grout section). Additionaly, redundant sensors were also installed to compensate for the possibility of losing some sensors during construction or beyond. Four groups of strain and temperature sensors were installed at:

(1) midspans and supports to monitor longitudinal stresses,

(2) midspans in the transverse direction to monitor lateral stresses,

(3) edges of deck panels to monitor the joints between panels,

(4) along the two sides of the grouted joint between the North and South panels.

Figure 1 shows the locations of the sensors installed at the Parkview Bridge. These sensors were used to capture data throughout the day at ten-minute increments to determine maximum and minimum values of stresses and temperatures recorded. Since the deck and beam act as a composite section after construction, sensors were placed near the top fiber of 


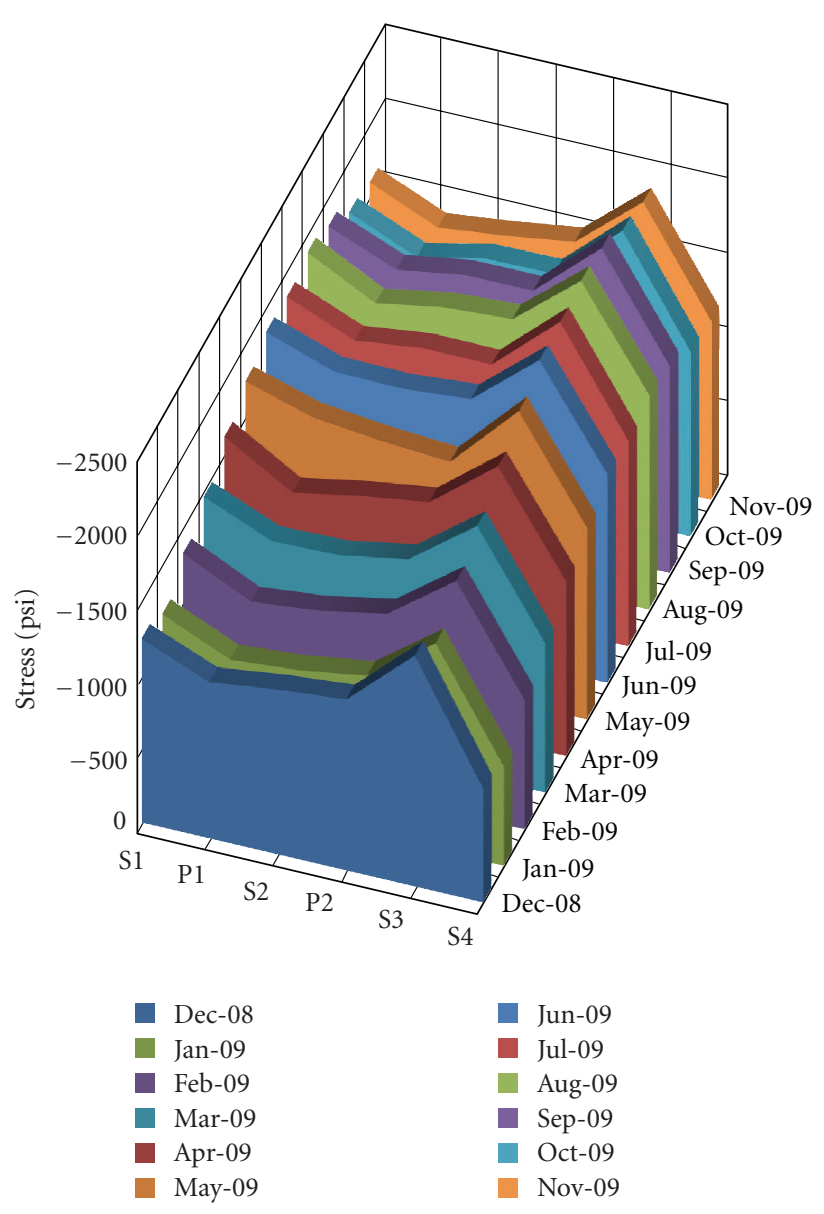

(a) Maximum

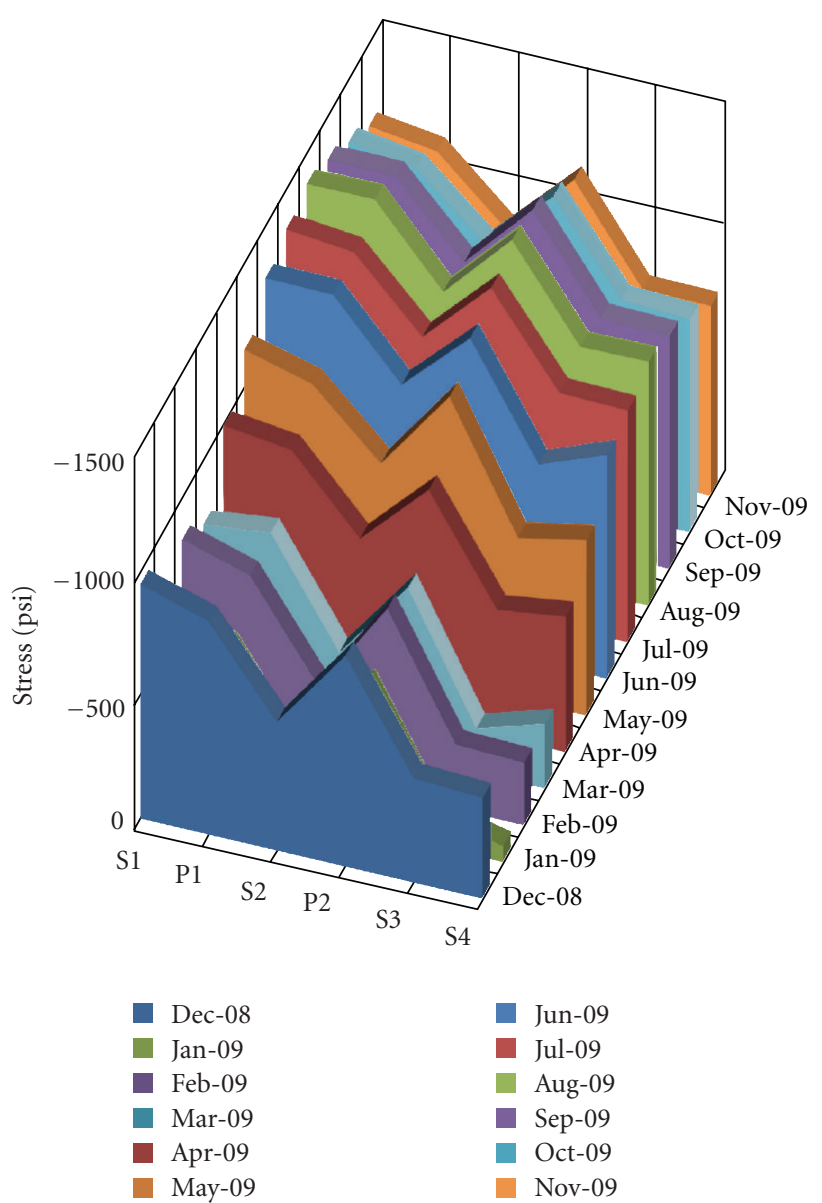

(b) Minimum

FIgURE 12: Maximum and minimum transverse stresses (psi)—north panels.

the section. Due to limitations by the owner, sensors were only placed in the deck.

\subsection{Sensor Hardware Installation. Attaching VWSG sensors} to reinforcing bars must follow a few precautions to ensure proper operation. In this study, all sensors were attached to the top reinforcement using zip ties with foam spacers to provide cover. Figure 3(a) illustrates the details of a properly secured sensor and how this configuration allows for the free flow of concrete mix while protecting the sensor and its wire during casting.

Once the sensors were properly attached to rebar, the wires connecting them to multiplexers were loosely coiled around the reinforcement to allow concrete bonding between the wires and the reinforcement and to prevent any damage that might occur to the wire during the placement of concrete. The wires were run to a four-inch diameter PVC pull boxes to protect them from the concrete during the pour and to provide accessibility to the wires after the installation of the deck panels at the bridge site. Each wire was labeled to indicate the sensor location and orientation after casting. Figure 3(b) shows a completed sensor network for a panel along with wire routing and pull box placement. Figure 3(c) illustrates the exposed pull box underneath the deck panels for access and splicing. Sensor wires were spliced together and run through PVC conduits underneath the deck panels to the data logging equipment.

In this project, the equipment was housed in three cabinets to protect the electrical equipment from varying environmental conditions, which were secured to the pier of the bridge as shown in Figure 3(d). Each data logger contains a modem for remotely communicating with the laboratory computer workstation for data transfer.

\section{The Parkview Bridge SHM Data Structure}

To effectively monitor the bridge performance under varying load conditions, sensors were grouped depending on their locations. In this study, four groups of sensors were used to monitor the bridge performance.

(1) Group 1: longitudinal stresses at mid spans and over the piers. 


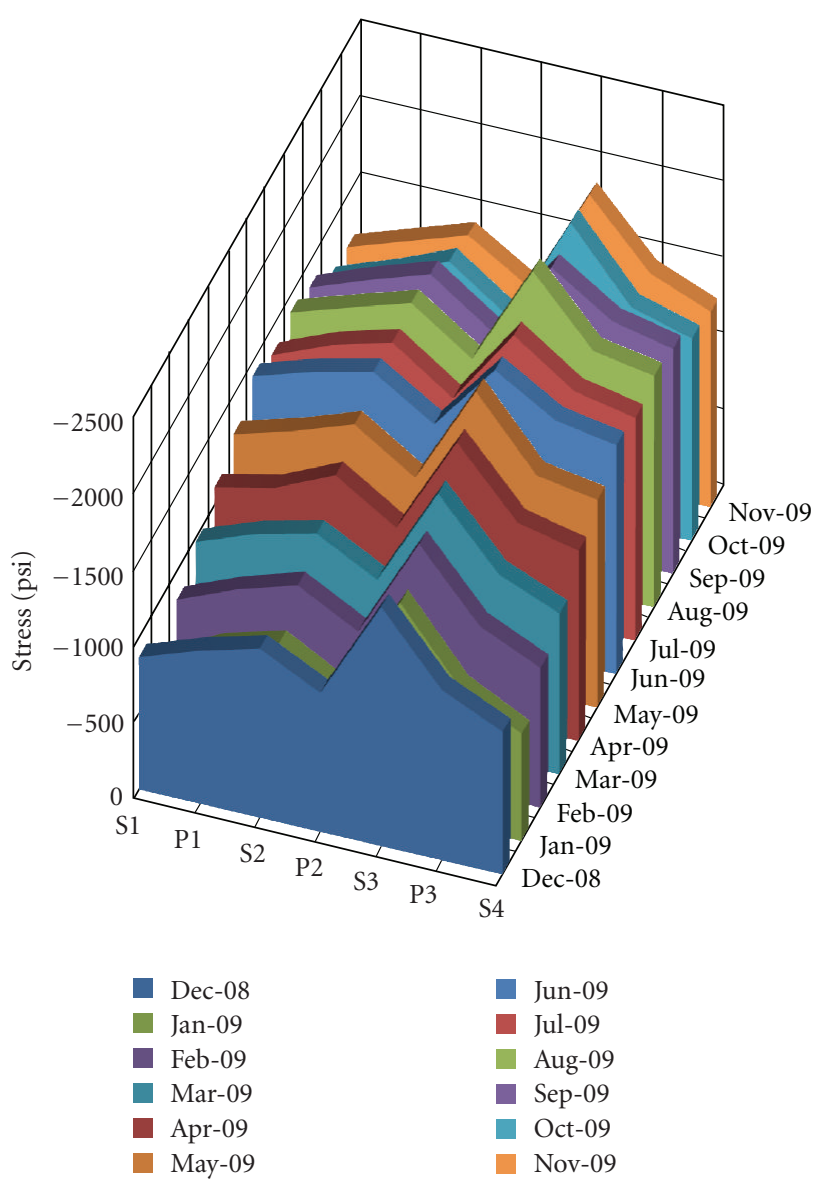

(a) Maximum

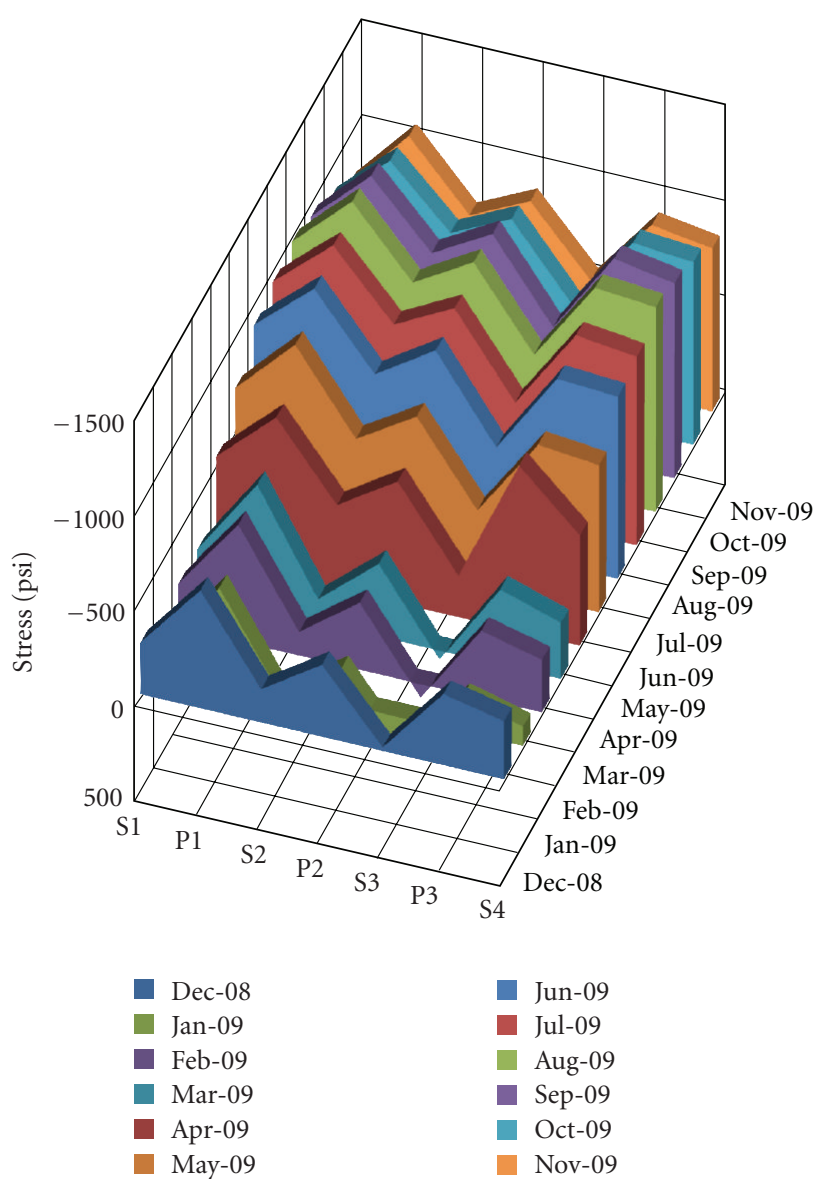

(b) Minimum

FIGURE 13: Maximum and minimum transverse stresses (psi)—south panels.

(2) Group 2: transverse stresses at mid spans.

(3) Group 3: stresses at joints between panels.

(4) Group 4: Stress at both sides of the cast-in-place grout between North and South panels.

Figure 1 shows the locations and labels of all the sensors in the panels and provides the group number for each sensor in parenthesis. If a sensor belongs to multiple groups, the numbers are separated by commas; for example, Group 1 refers to those sensors placed near mid spans and at pier locations, and orientated longitudinally near the traffic lanes to monitor longitudinal stresses. Table 2 summarizes the list of sensor labels that contribute to Group 1 in each panel.

Group 2 includes those sensors that are used to monitor the bridge performance under transverse loading. The locations are similar to those in Group 1, but oriented transversely. Table 3 lists all Group 2 sensors. Group 3 refers to those sensors along the edges of critical panels. The main reason for having this group of sensors is to monitor the bonding and load transfer of deck panels. Theoretically, the deck and girders should behave as a composite section, but environmental factors and loading may cause the composite section to behave as smaller sections if joints fail or show fatigue over time. Table 4 displays the sensors used for this category. Group 4 refers to those sensors that are placed along both sides of the center grout joining North and South panels. They are oriented longitudinally. Table 5 lists all sensors belonging to this group.

\section{Parkview Bridge SHM Data Acquisition and Analysis}

The deployment of the Parkview Bridge structural health monitoring system enabled the remote collection of continuous strain and temperature data. Real-time data are being collected at ten-minute intervals. The two data loggers are contacted weekly through the modems and dedicated telephone lines to download and archive the sensor data for future analysis. The raw strain data are converted into stress data using material properties based on the laboratory testing of concrete samples collected during casting. The SHM system started to function in December 2008. Data archiving for a period of three years is currently underway to develop a solid baseline for future continuous monitoring of this bridge's condition. Examples of data analysis are presented in this section to illustrate how such data is interpreted. 
TABLE 2: Sensors used for longitudinal load stress monitoring (Group 1).

\begin{tabular}{|c|c|c|c|c|}
\hline North panel & Sensor & Sensor & South panel & Sensor \\
\hline \multicolumn{5}{|c|}{ Span 1} \\
\hline 1 & N_1_C & & 1 & S_1_A \\
\hline \multicolumn{5}{|c|}{ Pier 1} \\
\hline 4 & N_4_C & & 4 & S_4_A \\
\hline \multicolumn{5}{|c|}{ Span 2} \\
\hline 7 & N_7_C & N_7_F & 7 & S_7_F \\
\hline 8 & N_8_C & N_8_F & 8 & S_8_F \\
\hline 9 & N_9_C & N_9_F & 9 & S_9_F \\
\hline \multicolumn{5}{|c|}{ Pier 2} \\
\hline 12 & N_12_C & & 12 & S_12_A \\
\hline \multicolumn{5}{|c|}{ Span 3} \\
\hline 15 & N_15_C & N_15_F & 15 & S_15_F \\
\hline 16 & N_16_C & N_16_F & 16 & S_16_F \\
\hline 17 & N_17_C & N_17_F & 17 & S_17_F \\
\hline \multicolumn{5}{|c|}{ Pier 3} \\
\hline 20 & N_20_C & & 20 & S_20_A \\
\hline \multicolumn{5}{|c|}{ Span 4} \\
\hline 24 & N_24_C & & 24 & S_24_A \\
\hline
\end{tabular}

Figure 4 shows the longitudinal stress monitoring for the North panels of Span 2 (Group 1) in January 2009. Note that a negative stress value represents compression. Also, note that the bridge deck is designed to be in compression (deck panels are posttensioned) at all times and that the maximum compression allowed is $-3600 \mathrm{psi}(-24,821 \mathrm{kPa})$ and the maximum allowable tension is $+537 \mathrm{psi}(+3702 \mathrm{kPa})$. The coinciding temperatures recorded are illustrated in Figure 5. Based on the limited information (one month in the first year), it is observed from Figure 5 that the differences in magnitudes between sensors as well as the slope of the lines over similar time periods are fairly similar (almost identical) with respect to temperature, suggesting a uniform behavior. The trend patterns for each sensor in Figure 4 demonstrate a uniform behavior as well.

Since all deck panels are fully restrained between supports, examining Figures 4 and 5 reveals that as temperature decreases, tension increases, reducing the total compression in the deck panels. It also reveals that as temperature increases, compression increases. This is clearly amplified in Figures 4 and 5 in the period from Tuesday 1/13/09 to Saturday $1 / 17 / 09$ where the temperature has decreased by 17 degrees Celsius, resulting in a decrease in compressive stress of about 500 pounds per square inch $(3447 \mathrm{kPa})$. The fluctuations between different locations are very minimal, indicating how little effect daily traffic has over the given time period and suggesting that temperature variation is the controlling factor in stress variation. The relationship between stresses and temperatures is key in this analysis, and any change in observed patterns over time may suggest that cracks are beginning to develop in the deck or that the deck is not acting as a fully composite unit (loss of bonding between joints).
When significant variations are noticed between stress lines of different sensors in similar locations over the same time period, further analysis should be performed to distinguish between abnormal and normal behavior. Examining Figure 4 reveals a steep change in stress over a single day from $1 / 17 / 09$ to $1 / 18 / 09$. Figures 6 and 7 isolate this day and display the data on an hourly scale. The trend is clearly similar for the sensors under consideration; temperature increased causing compressive stresses to increase. The slopes of the lines over the given time period in similar locations are very close and consistent. The difference in locations caused a slight difference in temperature, but the behavior is the same. When changes in consistency are noticed, a further investigation must be performed. Over the month of January, similar analyses were performed for all locations under this group and no concerns for safety or maintenance were noticed, which is expected since the bridge is new.

The stresses at the joints between panels are very important to monitor due to the unique nature of the Parkview Bridge design. To transfer stresses efficiently, the bond between panels must be maintained so that the deck behaves as a uniform composite member. Once again temperature had the greatest impact on stress fluctuation. The stresses are within allowable limits causing no concern for performance at this time. This investigation focused on the behavior of stress readings between adjacent panel edges. Figures 8 and 9 show the recorded values for the month of January. The stresses at the joint between North panels 7 and 8 (N_7_B and N_8_E sensors) were compared to each other. These sensors should provide similar stress patterns to demonstrate that bonding remains intact between the two different panels. If stress patterns were to change, then a closer look would be needed to determine causes for the change in pattern. If changes were to occur, the prediction would be that bonding had failed or cracks had developed to weaken the bond between the two panels. This analysis was performed on all sensors in this category (Group 3), and no concerns for performance or maintenance were noticed. Similar analyses were performed for the other groups of sensors and similar observations and conclusions had been obtained.

Tables 6 and 7 and Figures 10-13 illustrate the monthly maximum and minimum stress levels experienced at critical points (mid spans and piers) in longitudinal and transverse directions during the one-year monitoring. While there is no observed abnormal bridge deck behavior, there are a few instances that have experienced small tensile stresses in the transverse direction. Note that in these tables we are reporting the absolute maximum and minimum stresses experienced during a given month and that some of these readings may not necessarily be correct when the temperatures approach the lower sensor limit $\left(-20^{\circ} \mathrm{C}\right.$ or $\left.-4^{\circ} \mathrm{F}\right)$.

Once a three-year data set has been collected and the bridge deck behavior analyzed, stress envelopes can be developed to provide a baseline for normal maximum and minimum stress values. We feel that three years of stress data collection and analysis in the early stages of the bridge life-cycle are necessary to experience all stress scenarios from traffic, environmental, and bridge weight 
TABLE 3: Sensors used for transverse load stress monitoring (Group 2).

\begin{tabular}{|c|c|c|c|c|c|c|c|c|c|}
\hline North panel & Sensor & Sensor & Sensor & Sensor & South panel & Sensor & Sensor & Sensor & Sensor \\
\hline \multicolumn{10}{|c|}{ Span 1} \\
\hline 2 & N_2_A & N_2_B & N_2_D & & 2 & $\mathrm{~S} \_2 \_\mathrm{A}$ & S_2_C & S_2_D & \\
\hline \multicolumn{10}{|c|}{ Pier 1} \\
\hline 4 & N_4_D & N_4_F & & & 4 & S_4_E & S_4_F & & \\
\hline \multicolumn{10}{|c|}{ Span 2} \\
\hline 7 & N_7_D & N_7_D' & N_7_G & N_7_G' & 7 & S_7_E & S_7_E & S_7_G & S_7_G' \\
\hline 8 & N_8_D & N_8_D ${ }^{\prime}$ & N_8_G & N_8__ $\mathrm{G}^{\prime}$ & 8 & S_8_E & $\mathrm{S} \_8 \_\mathrm{E}^{\prime}$ & S_8_G & S_8_G $\mathrm{G}^{\prime}$ \\
\hline 9 & N_9_D & N_9_D' & N_9_G & N_9_G' & 9 & S_9_E & S_9_E' & S_9_G & S_9_G' ${ }^{\prime}$ \\
\hline \multicolumn{10}{|c|}{ Pier 2} \\
\hline 12 & N_12_D & N_12_F & & & 12 & S_12_E & S_12_F & & \\
\hline \multicolumn{10}{|c|}{ Span 3} \\
\hline 15 & N_15_D & N_15_D' & N_15_G & N_15_G' & 15 & S_15_E & S_15_E $E^{\prime}$ & S_15_G & S_15_G' \\
\hline 16 & N_16_D & N_16_D' & N_16_G & N_16_G' & 16 & S_16_E & S_16_E $E^{\prime}$ & S_16_G & S_16_G ${ }^{\prime}$ \\
\hline 17 & N_17_D & N_17_D' & N_17_G & N_17_G' & 17 & S_17_E & S_17_E $E^{\prime}$ & S_17_G & S_17_G ${ }^{\prime}$ \\
\hline \multicolumn{10}{|c|}{ Pier 3} \\
\hline 20 & & & & & 20 & S_20_E & S_20_F & & \\
\hline \multicolumn{10}{|c|}{ Span 4} \\
\hline 22 & N_22_B & N_22_D & & & 22 & S_22_C & S_22_D & & \\
\hline 23 & N_23_B & N_23_D & & & 23 & S_23_C & S_23_D & & \\
\hline
\end{tabular}

TABLE 4: Sensors used for stress monitoring at joints between panels (Group 3).

\begin{tabular}{|c|c|c|c|c|c|}
\hline $\begin{array}{l}\text { North } \\
\text { panel }\end{array}$ & Sensor & Sensor & $\begin{array}{l}\text { South } \\
\text { panel }\end{array}$ & Sensor & Sensor \\
\hline \multicolumn{6}{|c|}{ Span 1} \\
\hline 1 & N_1_B & & 1 & S_1_B & \\
\hline 2 & N_2_C & & 2 & S_2_B & \\
\hline \multicolumn{6}{|c|}{ Pier 1} \\
\hline 4 & & & 4 & & \\
\hline \multicolumn{6}{|c|}{ Span 2} \\
\hline 7 & N_7_B & & 7 & S_7_B & \\
\hline 8 & N_8_E & N_8_B & 8 & S_8_D & S_8_B \\
\hline 9 & & N_9_E & 9 & & S_9_D \\
\hline \multicolumn{6}{|c|}{ Pier 2} \\
\hline 12 & & & 12 & & \\
\hline \multicolumn{6}{|c|}{ Span 3} \\
\hline 15 & N_15_B & & 15 & S_15_B & \\
\hline 16 & N_16_E & N_16_B & 16 & S_16_D & S_16_B \\
\hline 17 & & N_17_E & 17 & & S_17_D \\
\hline \multicolumn{6}{|c|}{ Pier 3} \\
\hline 20 & & & 20 & & \\
\hline \multicolumn{6}{|c|}{ Span 4} \\
\hline 22 & N_22_A & & 22 & S_22_A & \\
\hline 23 & N_23_C & N_23_A & 23 & S_23_B & S_23_A \\
\hline 24 & & N_24_D & 24 & & S_24_D \\
\hline
\end{tabular}

TABLE 5: Sensors used for stress monitoring along cast-in-place grout (Group 4).

\begin{tabular}{|c|c|c|c|}
\hline North panel & Sensor & South panel & Sensor \\
\hline \multicolumn{4}{|c|}{ Span 1} \\
\hline 1 & N_1_C & 1 & S_1_A \\
\hline \multicolumn{4}{|c|}{ Pier 1} \\
\hline 4 & N_4_C & 4 & S_4_A \\
\hline \multicolumn{4}{|c|}{ Span 2} \\
\hline 7 & N_7_C & 7 & S_7_A \\
\hline 8 & N_8_C & 8 & S_8_A \\
\hline 9 & N_9_C & 9 & S_9_A \\
\hline \multicolumn{4}{|c|}{ Pier 2} \\
\hline 12 & N_12_C & 12 & S_12_A \\
\hline \multicolumn{4}{|c|}{ Span 3} \\
\hline 15 & N_15_C & 15 & S_15_A \\
\hline 16 & N_16_C & 16 & S_16_A \\
\hline 17 & N_17_C & 17 & S_17_A \\
\hline \multicolumn{4}{|c|}{ Pier 3} \\
\hline 20 & N_20_C & 20 & S_20_A \\
\hline \multicolumn{4}{|c|}{ Span 4} \\
\hline 24 & N_24_C & 24 & S_24_A \\
\hline
\end{tabular}

(creep) loads to enable the development of a representative set of stress envelopes (baseline). If stresses fall outside these envelopes, this would trigger further investigation to determine the cause(s) for the deviation and to recommend the course(s) of action. While a longer period is more 
TABle 6: Maximum and minimum stresses-north (psi)*.

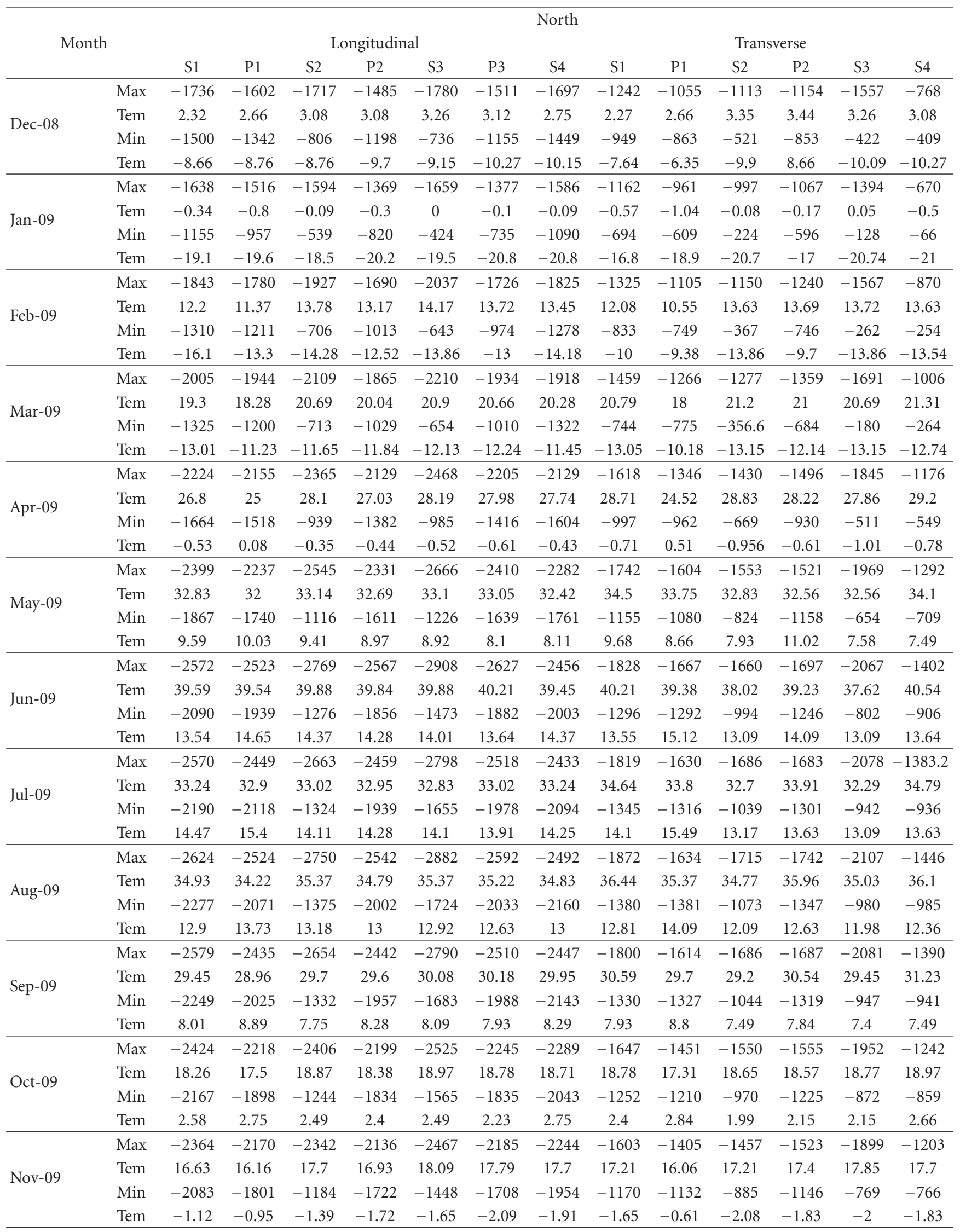


Table 7: Maximum and minimum stresses—south (psi)*

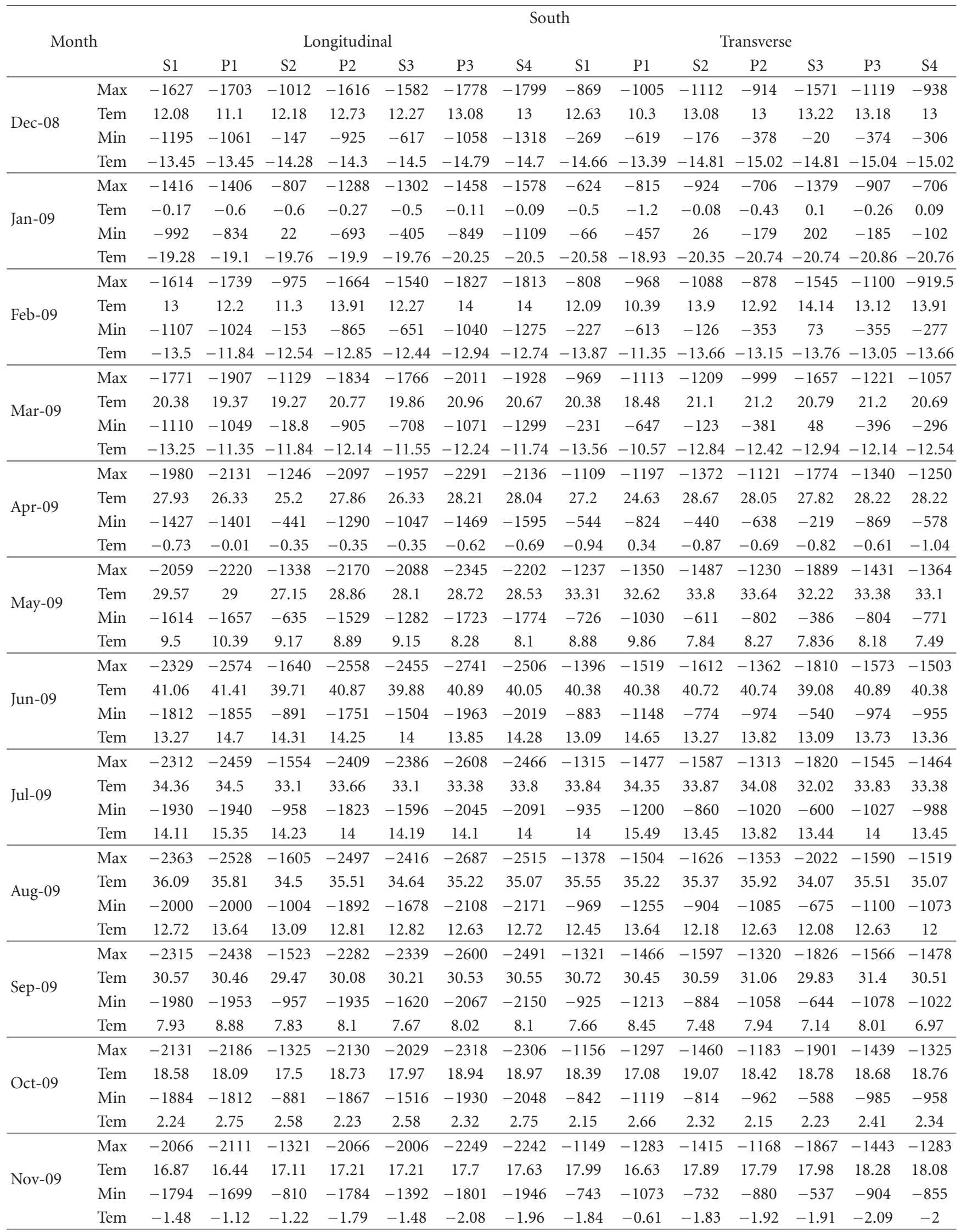

${ }^{*} 1 \mathrm{psi}=6.89474 \mathrm{kPa}$. 
desirable, we are limited in this study by the timeline as desired by the Michigan Department of Transportation (MDOT), where Phase I and II of this project will result in the design and construction of the system along with three years of sensor stress data collection to develop the baseline stress envelops and a deterioration prediction model based on finite element simulations. After phase II is completed, we hope to begin actual monitoring of the bridge for some period of time until we turn the bridge over to MDOT for life-cycle monitoring. Certainly, the three-year baseline can always be reassessed after many years of data have been collected beyond phase II to determine if additional years in the baseline may lead to better prediction results. At this time, a three-year period seems to be a reasonable predictor of the weather patterns in our area.

\section{Concluding Remarks}

A health monitoring system was designed and deployed for the Parkview Bridge in Kalamazoo, Michigan. It is anticipated that this sensor-based health monitoring system would be capable of providing continuous monitoring of the bridge deck to determine its condition, assess the impacts from environmental factors such as temperature and from traffic loads, evaluate its deterioration rate, initiate maintenance and repairs when needed, and predict the remaining service life. Even with limited preliminary data, meaningful observations regarding the bridge performance and the relationship between temperature and stress can be obtained. It was found that recorded stresses vary widely due to the combined effect from loading and temperature variations. However, it was concluded that temperature is the controlling factor in stress variations that are measured by the static sensors in this study. Variations in temperature cause the bridge's behavior to vary from season to season.

A few lessons were learned in this study. The first lesson is related to the installation of sensors which is found to need a formal quality control procedure. The method used for securing sensors worked fine, but could be further improved. For example, the foam spacers, which are tightened by zip ties, would occasionally fall out if disturbed before casting, especially when the workers were in contact with the reinforcement or stepping on the zip ties securing the sensors. To improve on this problem, workers should be prevented from standing over the rebar mesh when pouring concrete. A second lesson deals with sensor wire connections which present another challenge. Due to the large volume of sensors and wires being connected and spliced, strict supervision needs to be provided. The integrity of the project relies on proper sensor readings from known locations and orientations. The labeling and splicing processes must be carefully supervised to avoid errors in labeling sensors. A third lesson deals with the location of the cabinets that house the data loggers. While the cabinets are installed at the top of the pier, 16 feet (4.8 meters) high, to prevent unwanted access to the expensive equipment, this has posed an access challenge for maintenance when needed, particularly that the pier is very close to live highway traffic, requiring extra safety measures. A better approach would be to provide secured cabinets at the ground level for easy access.

Since the sensors use analog signals via telephone lines to communicate data, electrical noise interference can significantly affect the validity of the readings, degrading the signal. Strain data recorded by the sensors may show outof-range values that are caused by signal interference. Long cable lengths have been found to weaken and degrade the analog signal as well. When using a large volume of vibrating wire strain gages, it is recommended to use a minimum time of ten-minute intervals for continuous monitoring. Using shorter increments were found to cause several erroneous readings. Furthermore, depending on the number of arrays and frequency of data collection, capacity limitations of the data logger must also be determined. Prior estimates of capacity were determined to be two weeks when the actual capacity was closer to one. This has caused data to be overwritten and lost for that week.

We recognize that at this time the bridge is still new and is not expected to have problems. However, as time goes by, data covering a relatively long period of time will be collected and, when combined with a bridge deterioration model, can help predict bridge performance and call for timely preventative maintenance. We believe that three years worth of monitoring data would provide sufficient baseline information to create behavior envelopes that can be used for future prediction of bridge condition and can be the basis of a bridge deck deterioration prediction model. The following is a discussion of our future tasks that will need to be achieved to fully reap the benefit from the sensor network discussed in this paper.

(i) Stress Envelopes. Once large amounts of data have been collected and processed for a minimum recommended period of three years, envelopes can be developed to determine normal performance patterns and condition. This can provide fast and efficient assessment means for periodically evaluating the condition of the bridge deck in comparison to the design and behavioral limits.

(ii) Full-Depth Deck Performance and Health Condition Prediction Modeling. Since the bridge is new, it is too early to begin to understand how loads will impact the bridge's deck over time. Further analyses will be performed by finite element modeling, particularly at panel joints and at the closure grout, using actual strain data from the sensor network to shed additional insights on the health of the bridge deck. As more and more data is collected each year, these models could be adjusted, calibrated, and validated using the known behavioral strain data to simulate and develop defect signatures that would then be used for predicting the future behavior and condition of the bridge deck. 


\section{Acknowledgments}

The authors are grateful to the Michigan Department of Transportation (MDOT) for funding this study through MDOT Contract no. 04-0090/Z3. Any opinions, findings, conclusions, or recommendations expressed in this material are those of the authors and do not necessarily reflect the views of MDOT or Western Michigan University.

\section{References}

[1] Federal Highway Administration (FWHA), "Deficient bridges by state and highway system," U.S. Department of Transportation, 2007, http://www.fhwa.dot.gov/bridge/defbr07.cfm.

[2] B. Phares, T. Wipf, L. Greimann, and Y. Lee, "Health monitoring of bridge structures and components using smartstructure technology," Tech. Rep. 0092-04-14, Wisconsin Highway Research Program, WHRP 05-03, 2005.

[3] NCHRP-234, Manual for Bridge Rating through Load Testing, Research results digest, no. 234, National Cooperative Highway Research Program, Transportation Research Board, National Research Council, Washington, DC, USA, 1998.

[4] D. A. Howell and H. W. Shenton, "System for in-service strain monitoring of ordinary bridges," Journal of Bridge Engineering, vol. 11, no. 6, pp. 673-680, 2006.

[5] J. R. Casas and P. J. S. Cruz, "Fiber optic sensors for bridge monitoring," Journal of Bridge Engineering, vol. 8, no. 6, pp. 362-373, 2003.

[6] J. M. Ko and Y. Q. Ni, "Technology developments in structural health monitoring of large-scale bridges," Engineering Structures, vol. 27, no. 12, pp. 1715-1725, 2005.

[7] J. Olund and P. E. DeWolf, "Passive structural health monitoring of Connecticut's bridge infrastructure," Journal of Infrastructure Systems, vol. 13, no. 4, pp. 330-339, 2007.

[8] M. J. Chajes, H. W. Shenton, and D. O'Shea, "Bridge-condition assessment and load rating using nondestructive evaluation methods," Transportation Research Record, vol. 2, no. 1696, pp. 83-91, 2000.

[9] M. Cheung, W. Li, and B. Noruziaan, "Data acquisition, processing and management systems for a Canadian bridge monitoring project," in International Conference on Computing in Civil and Building Engineering, BauhausUniversitat, Weimar, Germany, June 2004, http://e-pub.uniweimar.de/volltexte/2004/128/pdf/icccbe-x_012.pdf.

[10] I. N. Robertson, "Prediction of vertical deflections for a long-span prestressed concrete bridge structure," Engineering Structures, vol. 27, no. 12, pp. 1820-1827, 2005.

[11] Y. Yang and J. J. Myers, "Live-load test results of Missouri's first high-performance concrete superstructure bridge," Transportation Research Record, no. 1845, pp. 96-103, 2003. 

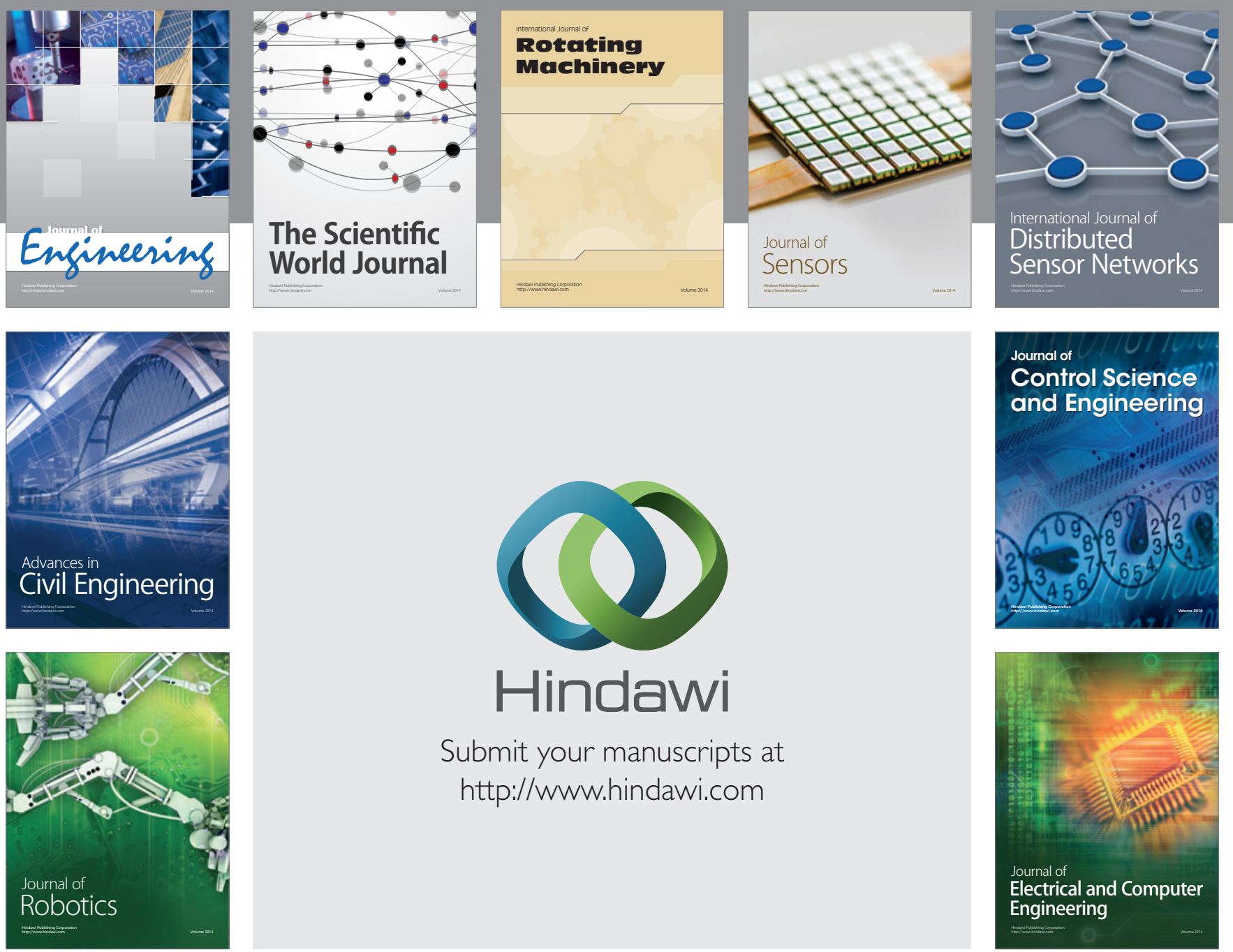

Submit your manuscripts at

http://www.hindawi.com
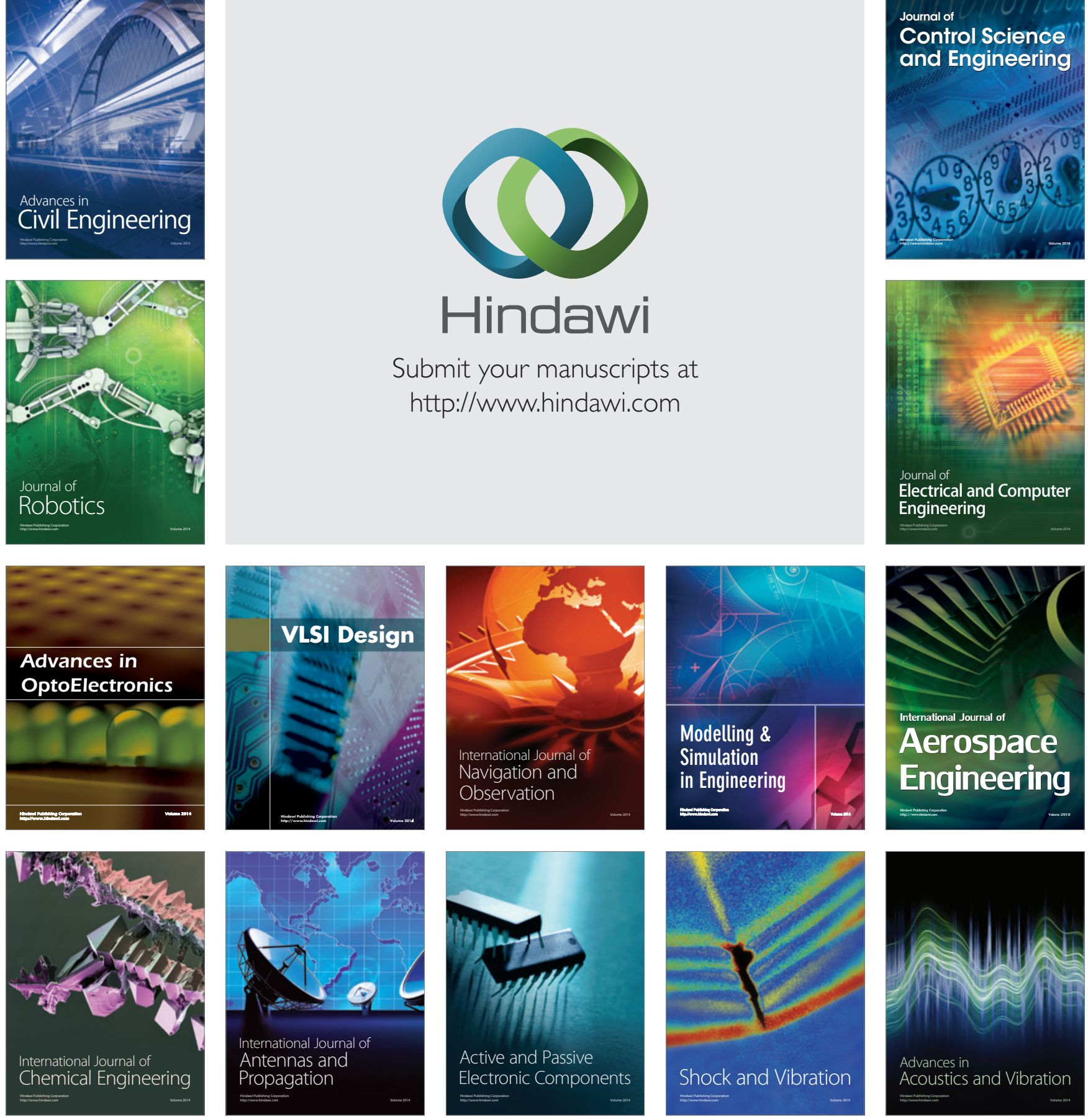